\title{
Sederek ve Şerur İli (Nahçıvan Özerk Cümhuriyeti/Azerbaycan) Florası ve Vejetasyonuna Katkılar
}

\author{
Musa CABBAROV ${ }^{1 *} \quad$ Elyar IBRAHIMOV ${ }^{2} \quad$ Fatmaxanım NABIYEVA $^{2} \quad$ Vagif ATAMOV $^{3}$ \\ ${ }^{1}$ Bakü Devlet Üniversitesi, Biyoloji Fakültesi, Botanik Kürsüsü, Halilov 23, Bakü/Azerbaycan. \\ ${ }^{2}$ Azerbaycan Milli Bilimler Akademisi Nahçıvan Şubesi, Biyolojik Kaynaklar Enstitüsü, Nahçıvan/Azerbaycan. \\ ${ }^{3}$ Recep Tayyip Erdoğan Üniversitesi, Fen-Edebiyat Fakültesi, Biyoloji Bölümü, Rize, Türkiye. \\ *D: https://orcid.org/0000-0003-0386-2207, (D): https://orcid.org/0000-0002-2780-5912 \\ (D): https://orcid.org/0000-0003-4841-3165, (D: https://orcid.org/0000-0002-6718-7979
}

Öz: Makalede Azerbaycan'a bağlı Nahçıvan Özerk Cumhuriyeti'nin Sederek ve Şerur İl sınırları içerisinde yer alan bölgenin flora ve vejetasyonu ele alınmıştır. Bölgede hakim olan frigana vejetasyonunda karakteristik olan bazı bitkiler meyve verimliliği yönünden araştırılmıştır. Bitki örtüsünde bazı faydalı bitki türlerinin bol yayılış gösterdiği ve rasyonel kullanım imkanlarının olduğu belirlenmiştir. Arazi çalışmaları sırasında toplanan bitki örnekleri içerisinde: Pyrus salicifolia Pall., Malus orientalis var. montana (Uglitzk.) Langenf, Pistacia mutica Fisch. \& C.A. Mey., Amygdalus fenzliana (Fritsch) Lipsky, Lonicera bracteolaris Boiss. et Buhse, Rhamnus catharicus L., Prunus spinosa L., Amelanchier ovalis Medik., Ziziphus jujuba Mill., Asperunginoides axillaris (Boiss.et Hohen) Rauschert, Centranthus longifolius Stev., Ribes nigrum L., Helosciadium nodiflorum (L.) W.D. J. Koch.vd. taksonlarında araştırma alanı içerisinde yayılış gösterdiği belirlenmiştir.

\section{Contribution to Flora and Vegetation of Sederek and Sharur (Autonomous Republic of Nakhchivan/Azerbaijan)}

\begin{abstract}
In this article, flora and vegetation in Sederek and Sharur provinces of Nakhchivan Autonomous Republic of Azerbaijan is discussed. Some dominant plants which are characteristics of the vegetation in the region have been studied in terms of fruit productivity. It has been determined that some useful plant species are abundant in the vegetation and they have rational usage possibilities. Examples of plants collected during field studies include: Pyrus salicifolia Pall.,Malus orientalis var. montana (Uglitzk.) Langenf, Pistacia mutica Fisch. \& C.A. Mey., Amigdalus fenzliana (Fritsch) Lipsky, Lonicera bracteolaris Boiss. et Buhse, Rhamnus catharicus L. Prunus spinosa L. Amelanchier ovalis Medik., Ziziphus jujuba Mill., Asperunginoides axillaris (Boiss.et Hohen) Rauschert, Centranthus longifolius Stev., Ribes nigrum L., Helosciadium nodiflorum (L.) W.D. J. Koch.and other taxa also were found to be distributed in the research area.
\end{abstract}




\section{GíRiş}

Nahçıvan Özerk Cumhuriyeti coğrafik olarak Güney Kafkasya'nın dağeteği kuşağında olan Azerbaycan Cumhuriyeti sınırları içerisinde yer almaktadır. Yüz ölçümü 5,5 bin $\mathrm{km}^{2}$ dir. Topografik olarak derin derelerle parçalanmış Zengezur ve Derelegöz dağ silsilelerinin yer aldığı bu arazi çok sayıda vadiler ile bölünmüştür (Azizbeyova, 1961). Derelegöz dağ silsilesinin güney-batısı araştırma alanın kuzey-batısını kapsamaktadır (Harita 1). Alanın en yüksek dağ zirveleri; Küküdağ (3113 m), Keçeldağ (3114 m), Karakuş (2795), Keçeltepe (2740 m), Sinodağ $(2905 \mathrm{~m})$, Gelinkaya $(2769 \mathrm{~m})$, Ordubinası $(2505,3 \mathrm{~m})$, Yağargedik (2047,7 m), Kemurludağ (2074 m), Ginadalı (2097,7 m), Remlyar (2278,8 m), Ardaklı (2226 m), vd.'dir. Araştırma alanının düz kesimleri Aras nehrinin sol sahilinde yer almaktadır. Bu kesimde çok da geniş olmayan ve birbirinden ayrı 7 ova (düzlük) yer almaktadır. Bunlar; Sederek, Şerur, Büyükdüz, Kengerli, Çelhankalı, Nahçıvan, Culfa-Ordubad düzleridir. Bu düzler Aras nehri sahilleri ile skk bağlantılı ve alan genişliği $1250 \mathrm{~km}^{2}$ 'dir.

Nahçıvan Özerk Cumhuriyeti arazisi zengin bir flora ve vejetasyona sahiptir. Bu yönü ile bölgede çok sayıda araştırmalar yapılmış (Gemberli, 1973; Grossheym, 1936, 1948; İbrahimov, 1973; Karyagin, (1950-1961); Prilipko, (1939-1970) ve bu çalş̧malar üzerinden yıllar geçmiştir. Sonuçta doğal flora ve bitki örtüsü tarihi, ekolojik, antropojenik vs. faktörlerin etkisiyle süksesyona uğramıştır. Bitki örtüsünde çok sayıda bitki birlikleri süksesyona uğramış, nadir veya soyu tükenme durumuna gelmiş, bazıları ise yok olmuştur (Grossgeym, 1939-1967).

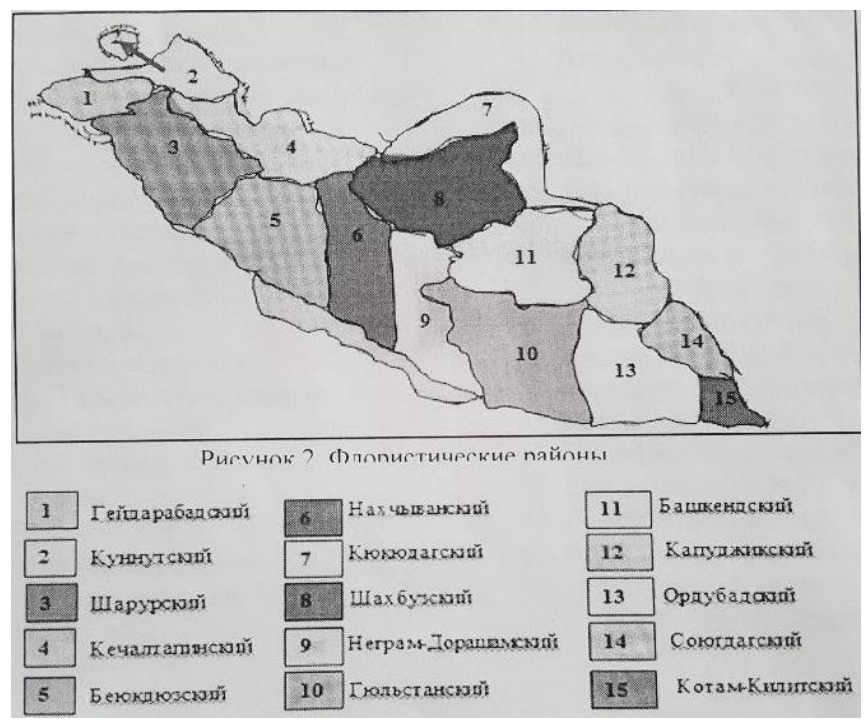

Şekil 1. Nahçıvan'in floristik ilçeleri haritası.

İlçeler: 1. Haydarabad, 2. Kunnut, 3. Şahbuz, 4. Keçeltepe, 5. Büyükdüz, 6. Nahcıvah,

7. Küküdağ, 8. Şahbuz, 9. Nehrem-Daraşam, 10. Gülüstan, 11. Başkent, 12. Kapudjik,

13. Ordubad, 14. Soyukdağ, 15 . Kotam-Kilit flora ilçeleri.

Araştırma alanı haritada 3, 5, 6 ve 8 no'lu floristik ilçeleri kapsamaktadır.

Bölge florasına göç etmiş bazı istilacı ve yabancı (ruderal, segetal, hidrofil, kosmopolit ve adventiv) türler de bulunmaktadır. Bundan dolayı amacımı Sederek ve Şerur İl sınırları içerisinde bu günkü ortam şartlarının etkisi ile bölgenin flora ve bitki örtüsünde gerçekleşmiş olan süksesyonel gelişmeleri detaylı bir şekilde araştırmak olmuştur.

\section{MATERYAL VE METOT}

Araştırma alanı Nahçıvan'ın Düzlük, Dağlık ve Yüksek dağlık arazilerini kapsamıştır. Araştırmada materyal olarak 2005-2015 yılları arasında toplanmış bitki örneklerinden faydalanılmıştır.

Bölgenin farklı kesimlerinden farklı mevsimlerde toplanmış bitkiler herbaryum örneği şekline getirilmiş, etiketlenmiş ve 8 ciltlik "Azerbaycan Florası" Karyagin, (1950-1961), ve "Kafkasya Florası" Grossgeym, (1939-1967) eserine göre teşhis edilmiştir. Herbaryum örnekleri Azerbaycan Milli Bilimler Akademisi Nahçıvan Bölmesi’nin Bitki Resursları Enstitüsü'nün Bitki Sistematiği şubesi herbaryumunda saklanmaktadır. Literatürde meyve verimliliğinin belirlenmesi, deneme alanlarının konfigürasyonu, sayısı, ölçüsü, yerleştirilmesi, verilerin değerlendirilmesi, metodun ekonomikliliği gibi konularla ilgili bilgiler literatürlerde mevcuttur (Beydeman, 1954; Polevaya Geobotanika,1959-1976; Metogika Fenologiçeskikh Nablyudeniya Pri Botaniçeskikh Issledovaniyakh, 1966).

Meyve verimliliği, potansiyeli, rezervi ile ilgili örneklik alanların belirlenmesi için belirli güzergâhlarda örnek parseller belirlenmiştir. Arazi çalışmalarında örnek parsellerin konulacağı alanlar belirlenmiş ve her parselden 3$4 \mathrm{kez}$ numune alınmıştır. İstasyonlar içerisinde yer alan ağaç ve çalıların sıklığı, örtüş derecesi tespit edilmiştir. Homojen bir fitososyolojik yapıya sahip olan $400 \mathrm{~m}^{2}$ ölçüde bir deneme alanı seçilmiş ve bu alanda yer alan ağaç ve çalıların birey sayıları sayılmıştır.

Örneklik alanlar Ayıderesi, Çeşme etrafi, Tala Ormanı, Susuz, Armutluk Ormanı ve Karakuş’tan seçilmiş̧ir. Örnek parsel alanında yer alan toplam birey sayıs belirlendikten sonra meyve bitkilerinin (erik, armut, garağat, elma, başınağac gibi) doğal verim potansiyeli ortaya konmuştur.

Vejetasyon çalışmaları zamanı Polevaya Geobotanika (1959-1976) eserinde verilmiş yöntemlerden, taksonların adları ve otör isimlerinde ise Çerepanov (1995) ve Kafkasya Florası Konspekti (2003; 2006; 2008; 2012) eserlerinden faydalanılmıştır.

Bölgede yayılış gösteren bazı yabani meyve türlerinin Pyrus salicifolia Pall., Malus orientalis var. montana (Uglitzk.) Langenf, Pistacia mutica Fisch. \& C.A. Mey., Amygdalus fenzliana (Fritsch) Lipsky, Lonicera bracteolaris Boiss. et Buhse, Rhamnus catharicus L., Prunus 
spinosa L. mevsimsel biyoekolojik özellikleri (bolluğu, verimliliği ve tedarik potansiyeli) değerlendirilmiştir. Ayıderesi, Kazmaderesi, Cehennemderesi, Bağırsakderesi ve Danakalası mevkilerinde 5 deneme alanı belirlenmiş ve bu bitkilere ait 12 birey numaralandırılmış.

Botanik araştırmalarında Fenolojik Müşahede Medotları (1966) kitabından faydalanılarak deneme alanlarında seçilmiş ve numaralandırılmış bitkilerde çiçek ve meyve oluşumu dönemlerini kapsayan fenolojik gözlemler yapılmıştır.

\section{BULGULAR}

Günümüzde besin değeri yüksek olan doğal ürünlerin temin edilmesinde yabani bitkilerin rolü önem kazanmıştır. Gıda, tıbbi ve diğer faydalı özelliklere sahip bitkilerin olduğu bölgelerde tedarik imkânlarının daha da artırılması istenmektedir. Günümüzproblemlerinin biri de yabani meyve türlerinin verimliliğinin teşhis edilmesi ve ürüne dönüşmesi yollarının belirlenmesidir.

Mevcut taksonların (familya, cins ve türlerin) oluş̧urduğu bir doğal bütünlük o bölgenin florasını oluşturur. Buna bağlı olarak elimizden geldiği kadar araştırılan bölgenin florasını toplamaya çaba gösterilmiş ve bölgenin florası ile bağlı yeni özellikler ortaya konmaya çalışılmıştır. Araziden toplanan bitkiler detaylı bir șekilde araştırılmış, teşhis edilmiş ve sinıflandırılmış̧ır. Sonuçta bölgede yayılış gösteren meyve özellikli ve tıbbi yönden faydalı, nadir ve soyu tükenme tehlikesi olan bitkiler belirlenmiştir.

Sederek ve Şerur İl sınırları içerisinde yayılış gösteren bitkilerin familyalara göre cins ve tür dağılımı belirlenmiștir (Tablo 1.).

Tablo 1.'de görüldüğü gibi Nahçıvan arazisinde toplam 580 cinse ait 2072 türe rastlanılmaktadır. Bunlardan 214 cinse ait 711 türün Sederek ve Șerur Il sınırları içerisinde yayılıș gösterdiği belirlenmiștir. Cins ve tür sayısına baktığımızda; Asteraceae Dumort., Poaceae Barnhart., Rosaceae Adans., Fabaceae Lindl., Caryophyllaceae Juss., Lamiaceae Lindl., Brassicaceae Burnett ve Apiaceae Lindl. familyalarının daha zengin olduğu gözükmektedir. Tür sayıs1 51-88 arasında değişen 5 familya yer almaktadır. Araştırılan bölgenin florasında 57 cinse ait takson sayısının daha fazla olduğu, özellikle; Bromus L., Bromopsis Fourr., Poa L., Stipa L., Ranunculus L., Papaver L., Dianthus L., Gypsophila L., Minuartia L., Silene L., Atriplex L., Chenopodium L., Salsola L., Rumex L., Viola L., Populus L., Salix L., Erysimum L., Alyssum L., Lepidium L., Euphorbia L., Sedum L., Alchemilla L., Crataegus L., Potentilla L., Pyrus L., Rosa L., Astracantha Podlech, Astragalus L., Lathyrus L., Medicago L., Onobrychis Hill, Trigonella L., Vicia L., Pimpinella L., Valerianella Hill, Campanula L., Artemisia L., Centaurea L., Cirsium Hill, Cousinia Cass., Helichrysum Mill., Hieracium L., Inula L., Pyrethrum Zinn., Scorzonera L., Senecio L., Tragopogon L., Galium L., Scrophularia L., Verbascum L., Veronica L. cinslerine ait taksonların bölgenin bitki örtüsünde önemli rol oynadı̆̆ı görülmektedir (Karyagin, 1950-1961; Grossheym, 1939-1967); (Talibov ve İbrahimov, 2008).
Tablo 1. Araştırma alanında yaygın olan familyalara göre cins ve tür dağılımı.

\begin{tabular}{|c|c|c|c|c|c|c|c|c|c|}
\hline \multirow{2}{*}{ № } & \multirow{2}{*}{ Familyalar } & \multicolumn{4}{|c|}{ Nahcivan Ö.C. arazisinde } & \multicolumn{4}{|c|}{ Araștırma alanında } \\
\hline & & Cin & $\%$ & Tür & $\%$ & Cins & $\%$ & Tür & $\%$ \\
\hline 1. & Poaceae Barnhart. & 95 & 16,37 & 297 & 14,33 & 29 & 13,55 & 78 & 10,97 \\
\hline 2 & Asteraceae Dumort. & 89 & 15,34 & 337 & 16,26 & 31 & 14,48 & 120 & 16,87 \\
\hline 3 & Brassicaceae Burnett & 66 & 11,37 & 165 & 7,96 & 15 & 7,00 & 53 & 7,45 \\
\hline 4 & Apiaceae Lindl. & 56 & 9,66 & 105 & 5,06 & 19 & 8,87 & 32 & 4,50 \\
\hline 5 & Fabaceae Lindl. & 47 & 8,10 & 258 & 12,45 & 10 & 4,67 & 82 & 11,53 \\
\hline 6 & Caryophyllaceae Juss. & 32 & 5,51 & 109 & 5,26 & 9 & 4,20 & 30 & 4,21 \\
\hline 7 & Lamiaceae Lindl. & 30 & 5,17 & 128 & 6,17 & 7 & 3,27 & 47 & 6,61 \\
\hline 8 & Chenopodiaceae Vent. & 30 & 5,17 & 76 & 3,66 & 14 & 6,54 & 40 & 5,62 \\
\hline 9 & Rosaceae Adans. & 30 & 5,17 & 153 & 7,38 & 8 & 3,73 & 45 & 6,32 \\
\hline 10 & Boraginaceae Adans. & 25 & 4,31 & 60 & 2,89 & 12 & 5,60 & 19 & 2,67 \\
\hline 11 & Scrophulariaceae Boiss. & 18 & 3,10 & 88 & 4,24 & 7 & 3,27 & 25 & 3,51 \\
\hline 12. & Ranunculaceae Adans. & 15 & 2,58 & 57 & 2,75 & 16 & 7,47 & 22 & 3,09 \\
\hline 13 & Cyperaceae Boiss. & 13 & 2,24 & 51 & 2,46 & 11 & 5,14 & 18 & 2,53 \\
\hline 14 & Polygonaceae Boiss. & 10 & 1,72 & 34 & 1,64 & 7 & 3,27 & 20 & 2,81 \\
\hline 15 & Rubiaceae Boiss. & 8 & 1,37 & 38 & 1,87 & 6 & 2,80 & 17 & 2,39 \\
\hline 16 & Hyacinthaceae Batsch. & 7 & 1,20 & 23 & 1,11 & 5 & 2,33 & 13 & 1,82 \\
\hline 17 & Liliaceae Juss. & 4 & 0,68 & 34 & 1,64 & 4 & 1,86 & 16 & 2,25 \\
\hline 18 & İridaceae Juss. & 3 & 0,51 & 23 & 1,11 & 3 & 1,40 & 10 & 1,40 \\
\hline 19 & Alliaceae J.Agardh. & 2 & 0,17 & 36 & 1,73 & 1 & 0,46 & 24 & 3,37 \\
\hline & Toplam & 580 & 100 & 2072 & 100 & 214 & 100 & 711 & 100 \\
\hline
\end{tabular}

$\mathrm{Bu}$ cinsler arasinda: Astragalus L. (69 takson), Silene L. (25 takson),Vicia L. (25 takson), Rosa L.(33 takson), Centaurea L. (24 takson), Crataegus L. (20 takson) tür sayısı daha baskındır. Diğer cinslerde tür sayısı 10-19 arasında değişmektedir. Malus orientalis var. montana (Uglitzk.) Langenf, Pistacia mutica Fisch. \& C.A. Mey., Amigdalus fenzliana (Fritsch) Lipsky, Lonicera bracteolaris Boiss. Et Buhse, Rhamnus catharicus L. gibi tek türle temsil olunan fakat bölgede yayılışı geniş olan taksonlar da mevcuttur. $\mathrm{Bu}$ türlerin baskın bir popülasyonda olması bölgede ekonomik öneme sahip olduğunu göstermektedir.

Bölgede doğal bir anıt niteliğinde olan Ziziphus jujuba Mill. (Hünnab) türüne Çarakdaş kayaları çevresinde yoğun, Sederek ve Kerki köyleri arasında ve Cihennemcarası, Kürtbabadağ 1 mevkilerinde ise seyrek olarak rastlanmaktadır. Ancak köy muhtarının anlattıklarına göre Sederek bölgesindeki hünnabın (Ziziphus jujuba Mill.) baskın olduğu bu bölge aşırı derecede tahrip edilmiştir. Hünnabın yayılış gösterdiği bu alanda 4-5 yıl öncesine kadar 160 adet bulunurken günümüzde aynı lokalitede 25 adet hünnab bireyine rastlanılmıştır.

Elaeagnaceae familyasına ait ve bölge için ekonomik değere sahip olan Hippophoae rhamnoides L. (yalancı iğde) türüne Lizburtderesi, Bağırsakderesi vadilerinde rastlanılmıştır.

Dikensiz Sakız ağacı (Pistacia mutica Fisch. \& C.A. Mey.) türüne sadece Kunnut dağı yamaçlarında yerleşen Sederek, Zaqatzip, Yaycı ve Gümüşlü köyleri çevrelerini kapsayan arid seyrek orman birlikleri içerisinde rastlanmıştır.

$\mathrm{Bu}$ bölgelerde Pistacia mutica bol meyve vermektedir. Eskiden yöre halkı bu bitkinin odunundan yakacak olarak faydalanmıştır. $\mathrm{Bu}$ bitkinin odunundan hazırlanan kömür ise günümüzde semt pazarlarında satılmaktadır. Bundan dolayı aşırı kesim nedeni ile bazı yerlerde fistık birliklerine sık bazı yerlerde ise nadir olarak rastlanılmaktadır.

Pistacia mutica türünün baskın olarak Eşeklimeydanı, Kazmaderesi, Kurbağaderesi, Kahalar, Başağıl, Bozagıl, Tejkap gibi yaşam yerlerinin yakınlarında rastlanılmaktadır. Kerki (Ejdekan dağı) köyü yakınlarında yayılış gösteren Juniperus polycarpos (çokmeyveli ardıç) bölge halkı tarafından yaygın olarak kullanılmaktadır. Bu köylerde yaşayan yerli halk Juniperus polycarpos bireyleri 
içerisinde gösterişli gövdeye sahip olan örneklerini yılbaşı ağacı ve inşaat malzemesi olarak kesmektedirler.

Şerur İl sınırları içerisinde Pyrus salicifolia Pall. (söğüt yapraklı armut), Malus orientalis var. montana (Uglitzk.) Langenf (Dağ elması), Pistacia mutica Fisch. \& C.A. Mey. (Dikensiz Sakız ağac1), Amygdalus fenzliana (Fritsch) Lipsky (Dağ bademi), Rhamnus catharicus L. (Akdiken) ve Prunus spinosa L. (çakal eriği) taksonlarının yaygın olarak iştirak ettiği bitki birliklerinin fitososyolojik yapısında bu taksonlar saf ve karışı birlikler oluşturmaktadır.

Nitraria schoberi L. türüne bölgede Kerimbeyli, Halaj, Tumaslı, Puryan, Hok, Kıvrak, Şahtahtı, Barmaziyar köylerin çevresinde az sayıda rastlanılmaktadır.

Yöre halkı eski devirlerden günümüze kadar gövdeleri 4-5 (bazen 7-8) metreye kadar boylanabilen Nitraria schoberi türünü bahçelerinde yetiştirmektedir. Tuza dayanıklı bu bitkinin gövdesi 8-9 (10-12) metreye kadar ulaşabilen, geniş şemsiyemsi bir dallanmaya sahip ağaç olarak her yil bol miktarda meyve vermektedir.

Araştırma alanı bitki örtüsünün fitososyolojik yönden araştırılması süresince bilimsel ve pratik yönden değerli çok sayıda bitki birliklerine, assosasyonlara rastlanılmıştır. Arazide yerleşim yüksekliğine göre üç vejetasyon tipi belirlenmiştir.

Birincisi Aras nehri Tezekent köyünden Hok ve Kerimbeyli köyü istikametine kadar olan: halofitik çöl ve yavşanlı yarıçöl vejetasyonunun yaygın olduğu bölgedir.

İkincisi Aras nehrinden; Sederek, Tahahama, Gümüşlü, Dapakent, Daşarh, Yenikent (1100 m) yönünde ve daha yüksek kesimlere kadar olan $(1800 \mathrm{~m})$ dağ kserofit ve dağ bozkırlarının yaygın olduğu bölgedir.

Üçüncü ise; 1800-2800 m ve daha yükseklerde yer alan, subalpin çayırlar, bozkırlaşmış çayırlıklar, seyrek ormanlıklar ve çalı birliklerinin yaygın olduğu bölgelerdir.
Bölgenin frigana birliklerinin, makro ve mikro gruplaşmaların oluşumunda; Astragalus microcephala (Willd.) Podlech, A. karjaginii (Boiss.) Podlech, A. lagurus Willd., Onobrychis cornuta (L.) Desv., Acantholimon karelinii (Stschegl.) Bunge, A. caryophyllaceum Boiss. vb. taksonların iştirakı, edifikatör ve karakter tür olarak birliklerin fitososyolojik yapısında iştirak etmektedirler (şekil. 1-6).

Aras nehri etrafı düzlüklerinde (Sederek düzü, Şerur düzü ve Böyükdüz) topraklar halofitleşmiş ve yıllık toplam yağmurun kısıtlı olması (250 mm'den az) ile karakteristiktir. Geniş alanlarda Kıvrak Şahtahtı köyleri çevresinde, Aras nehri kıyıları boyu halofitik bitkiler: Kalidium caspicum (L.) Ung., K. foliatum (Pall.) Moq. Hok, Salsola dendroides Pall., S. soda L.yayılış göstermektedir. Çukur yerlerde halohigrofil ve saf hidrofil birliklerine rastlanılmaktadır. Nahçıvan arazisinde daha nemli, substratınzengin ve tamamen suya batmış yerlerinde ise Salicornia europea L. türünün saf birliklerine (assosasyonlarına) rastlanılmaktadır.

Salsola dendroides Pall. ile bir arada Petrosimonia brachiata (Pall.) Bunge, P. glauca (Pall.) Bunge, Suaeda altissima (L.) Pall., Seidlitzia florida (Bieb.) Bunge. taksonlarıgeniş alanda yayılış göstermektedir. İlk defa Salsoletum birlikleri ile Halostachys belangeriana (Moq.) Botsch. ve Halocnemum strobilaceum (Pall.) Bieb. taksonlarının Hok, Şahtahtı, Tezekent, Diyatsin, Pisyan, Karakaçanlı, Halaj, Demirli, Ketadj, Arıbatan köylerin çevresinde baskın olduğu tarafımızdan kaydedilmiştir.

Araştırma alanının denizden 1100-1200 m yüksekliklerinde kseromorf jipsli habitatlar yer almaktadır. Kaydedilen halofitik bitkilerle birarada Nitraria schoberi L. ve Solanum nigrum L. türlerine de rastlanılmıştır. Sonbahar sonu meyveleri olgunlaştı̆̆ında yenilen bu bitkiler alanda geniş yayılış göstermektedir.
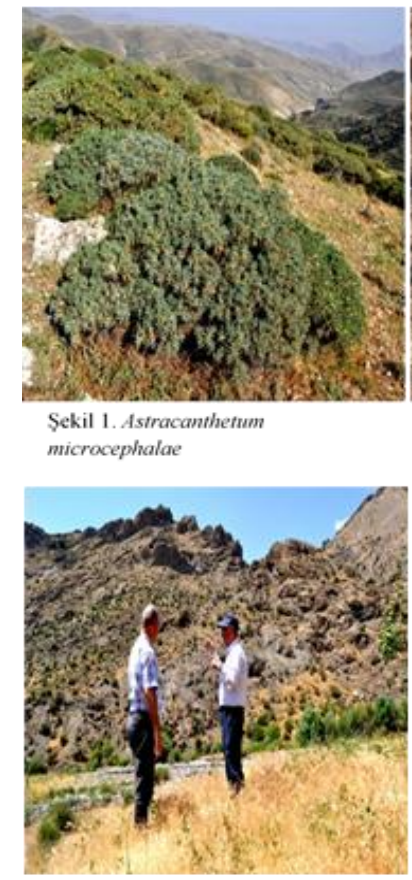

Sekil 4. Amvgdaleto-Astracantetum mycroplyyllae

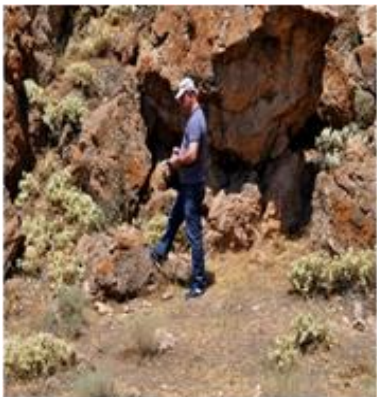

Şekil 2. Astragaleto-Stachyetum Inflatae

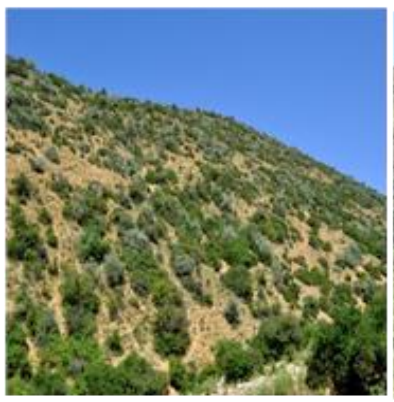

Sekil 5. Thymeto-Acantholimonetum bracteatumae

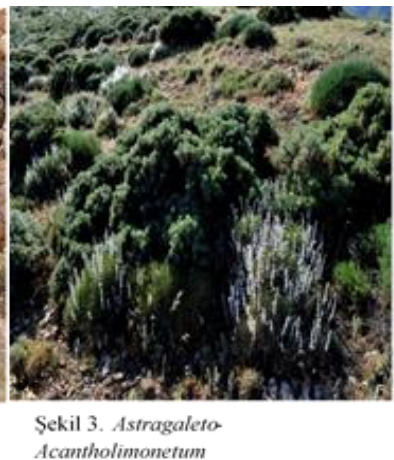

Acantholimanetum

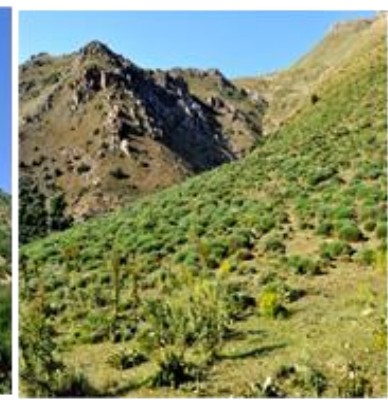

Sekil 6. Onobnychyetum cormutae 
Bölgenin dağlık kuşaklarında karışık çalı ve arid seyrek orman formasyonunda Ziziphus jujuba Mill., Sederek il sınırları içerisinde yer alan; Kerki, Danzik, Gümüşlü, Djagadzir, Aşağıyaycı, Gamzali, Yukarıyaycı, Ahura ve diğer köylerin etrafinda ise Pistacia mutica geniş yayılmaktadır. Ejderkan dağı Armutlu ve Ayıderesi yaylası Tananam köyü ile Ayıderesi arasında yer alan Elligedikde Malus orientalis, Danakalesı ve Ahura köyü ile Karakuş dağları arasında Cornus mas, Kazmaderesi ile Kürtbabaderesi arasında ise Pistacia mutica ve Juniperus polycarposbaskın olarak yayılıṣ göstermektedir. Bölgede Crataegus (Adi alıç), Rosa (kuşburnu), Berberis (Kadın tuzluğu), Rhamnus (cehri), Pyrus (armut) vb. cinslere ait olan türlerin yayıllış gösterdiği karışık çalı birlikleri bu bölgelerde geniş yayılmıştır.

Dağların kuru ve yer-yer otsu yamaçları Amygdalus fenzliana ve Rhamnus pallasii gibi arid seyrek orman birlikleri ile örtülüdür. Bu bitkiler ve onların oluşturduğu fitosenozlar yabani meyve bitkilerinin doğal reservini oluşturmaktadır.

İl sınırları içerisinde piyasa değerine sahip çok sayıda yabani meyve türlerine rastlanılmaktadır. Yörede doğal yayılış gösteren bazı yabani meyve türleri özel bir işleme tabi tutulmadan doğal olarak veya pişirilmiş şekilde yiyecek olarak kullanıldığ bilinmektedir. $\mathrm{Bu}$ bitkiler içerisinde kızılcık (Cornus mas) ve kadıntuzluğu (Berberis vulgaris L., Berberis iberica Stev. Et Fisch.) türlerinin şubat sonu erken çiçek açtığı ve çiçeklemenin nisanın sonu ve mayısın ilk yarısına kadar sürdüğü belirlenmiştir. Malus orientalis, Pyrus salicifolia, Amygdalus fenzliana nisan başından haziranın ortalarına kadar, Crataegus caucasica $\mathrm{C}$. Koch, Amelancher rotundifolia (Lam.) Dum., Lonicera bracteolaris Boiss. et Buhse ise mayısın başlarından temmuzun başlarına kadar çiçek açma fenofazında olduğu gözlemlenmiştir. Cerasus mahaleb (L.) Mill. (mahlep) ise haziran başlarında çiçek açmaya başlamaktadır.

Rosa cinsine ait 600 taksondan Kafkasya'da 56, Azerbaycan'da 42, Nahçıvan'da ise 21 taksona rastlanılmaktadır (Karyagin, 1937-1967, Azerbaycan florası, 5. cilt). Bazı taksonlarda meyve olgunlaşması ağustos başında, bazıları ise ağustos sonu veya ekimin başında, Berberis vulgaris, Berberis iberica (Kadın tuzluğu) meyve olgunlaşması ise kasım sonunda, erik ve doğu adi alıç türlerinin meyve olgunlaşması ise ekim sonunda gerçekleşmektedir. Dikey kuşaklanmaya bağlı olarak aşağı ve orta dağ kuşaklarında meyve işlenmesi için en uygun hazırlık dönemi ağustosun sonu eylül başı, yüksek dağlık kuşaklarda ise eylülün ikinci yarısından kasımın başlarına kadar olan sürenin en uygun olduğu belirlenmiştir.

\section{TARTIŞMA ve SONUÇ}

Azerbaycan arazisi sınırları içerisinde dağ kserofit vejetasyonu geniş olarak Nahçıvan'ın orta dağ ve Talış'ın yüksek dağlık (Diabar/Zuvand) bölgesinde, lekeler şeklinde ise Gobustan, Bozdağ silsilesi ve Karabağ'ın güney kesimlerinde yayllış gösterdiği bilinmektedir (Prilipko,1939; 1970).

Talış'ın Zuvand (Diabar) bölgesinde yayılış gösteren dağ-kserofit birlikleri ile Nahcıvan Özerk Bölgesinin ve İran'ın dağ kserofitleri arasında ortak fitososyolojik özelliklerin olduğu bilinmektedir (Hacıyev vd.,1979; Hacıyev vd.,1990).

Lerik İli Kosmalyan köyü çevresindeki güney yamaçlarda dikenli gevenlerin Astragalus aureus, A. picnophyllus, A. strictofoliusbaskın olarak yayılış gösterdiği,bazen Onobrychis cornuta, Acantholimon hochenaceri ve $A$. bracteatum türlerine de seyrek rastlanılmaktadır (Haciyev vd., 1990).

Nahçıvan ile komşu olan Ermenistan arazisinde de dağ-kserofit birliklerine rastlanıldı $\breve{g}$, subalpin çayırların daha zengin (120-140 tür) floraya sahip olduğu kaydedilmiştir (Magakyan, 1941).

Gürcistan'ın batısında kireçle zengin olan dağlık bölgelerinin florasında 92 familya ve 350 cinse ait 900 çiçekli bitki türünün olduğu bilinmektedir. Özellikle Campanulaceae ve Polypodiaceae familyalarma ait cinslerin önemli yer tuttuğu Kolşik bölgede 4 cinsin endemik olarak yer aldığı, Kolşik ve Kafkasya endemik türlerinin sayısının toplam Kafkas türleri florasının \% 22,4'ünü (203 tür) oluşturduğu da bilinmektedir (Sokadze, 1982).

Hacıyev vd., (1990) Küçük Kafkasyanın subalpin kuşağında takson sayısı yüksek dağ kesimlerinde 100, alpin çimenliklerinde ise 28-30(35) arasında seyreden bir floraya sahip olduğu kaydedilmiştir.

Nahçıvan genelinde yapılan arazi çalışmaları sırasında bölgeden toplanmış flora örnekleri içerisinde Nahcivan Özerk Bölgesi için yeni familya olarak; Ruppiaceae Hutch., Zannichelliaceae Dumort, cins olarak: Asperunginoides, Salicornia, Ruppia, Zannichellia, Abutilon, tür olarak ise: Ziziphus jujuba, Asperunginoides axillaris, Salicornia europaea, Abutilon tehophrasti, Tamarix octandra, Ruppia maritima, Zannchellia palustris teksonları ilk olarak kayıt edilmiştir. Bunun dışında Batabat ve Biçenek köyleri çevresinde 2 yeni alıç türünün (Crataegus pontica ve C. atrosanguinea) yayılış gösterdiği belirlenmiştir (Ibrahimov, 2005; Atamov, 2002; Talibov, 2001, 2003).

Bölgede yapılan floristik, jeobotanik ve reserve yönelik çalı̧̧malar bu güne kadar kaydedilmemiş Halostachys belangeriana (Moq.) Botsch, Halocnemum strobilaceum (Pall.) Bieb., Solicornia europaea L. gibi bilimsel ve pratik öneme sahip olan taksonların olduğu belirlenmiştir.

Prilipko, (1970) bu bölgede; Artemisetum itrchiana, Salsoletum nodulosae, Kalidietum, Anabasietum, Seidlitzietum gibi yarıçöl birlikleri dışında: ArtemisetoSalsoletum dendroisae, Artemiseto-Salsoletum nodulosae, Artemiseto-Halocemetum caspicae, Capparetum herbaceae, Euphorbietum seguerianae, Peganetum harmalae, Alhagetum persarum gibi çöl tipi bitki birliklerinin olduğu kaydetmiştir. 
Movsumova ve İbrahimov (1986), Talibov ve İbrahimov $(2008 ; 2018)$ tuzlu habitatların florasında Nitraria schoberi L. (Şöber şorgilesi) türününde yayılış gösterdiğini kaydetmiştir. Drupa (üzümsü) tipi ince kabuklu bir meyveye sahip olan bu bitkinin tohumu ile birlikte çiğ olarak yenen bir çalı türü olduğu bölge halkı tarafindan da bilinmektedir.

Kaynaklarda (Grossheym, 1939-1967; Karyagın, 1950-1961) Nitraria schoberi türünün Nahçıvan arazisi sınırları içerisinde yer almadığı görünür. Ancak bölgede gerçekleștirdiğimiz araştırmalar sırasında Sederek ve Kerki köylerinin 6-7 km kuzey-doğusunda Çarakdaş kayaları yakınlarında da Nitraria schoberi türünün yayılış gösterdiği tarafimızdan kaydedilmiştir.

Movsumova ve İbrahimov (1986) bölgenin halofitik çöl vejetasyonunun florasında 44 familya ve 160 cinse ait 265 çiçekli bitki taksonunun yayılış gösterdiğini, bu bitkilerden 195'inin (\% 47,2) çöl tipi vejetasyona ait karakteristik taksonlar olduğunu göstermiş̧ir.

Aras nehri boyunca, özellikle nehir kıy kesimlerinde 40-50 y1 sonra: Anabasis aphylla L., Halocnemum strobilaceum (Pall.) Bieb., Halostachys belangeriana (Moq.) Botsch., Kalidium caspicum (L.) Ung., Petrosimonia brachiata (Pal.) Bunge, Suaeda altissima (L.) Pall., S. dendroides (C.A.Mey.) Moq, Salsola dendroides Pall., S. crassa Bieb., S. nodulosa (Moq.) İljin, Seidlitzia florida (Bieb.) Bunge gibi çorak çöl bitkilerinin edifikatörlüğü ile halofitik çöl birliklerinin alanının daha da genişleyebileceği vurgulanmışlar (İbrahimov vd., 2018).

Araştırma bölgesinde yayılış gösteren ve “Azerbaycan'ın Kırmızı Kitabı”na dahil olan Gundelia tournefortii L., Crocus speciosus Bieb., Iris grossheimii Woronow ex. Grossh. Iris lucotis Woronow, Iris prilipkoana Kem.-Nath., Iris elegantissima Sosn., Iris caucasica Stev., Bellevalia pangistula (Miscz.) Grossh, Tulipa eichleri Regel, Tulipa julia C.Koch, Tulipa florenskyi Woronow, Ornithogalum ponticum Zahar., Allium akaka S.G. Gmel. Ex Schult. Fil., Allium woronowii (Miscz.) Grossh, Asparagus persicus Baker taksonların araştırma alanında tamamen koruma altına alınması gerektiği ortaya çıkmıştır (Azerbaycan Respublikasının kırmızı kitabı, 2013; Talibov \& \& İbrahimov, 2008).

Nahçıvan'in bitki örtüsünde; meşe (Quercus macrantherae Fisch.\& C.A.Mey.ex Hohen), meşe-dişbudak (Quercus macranthera-Fraxsinus excelsior), meşe-alıç (Quercus macranthera-Crataegus monogyna) gibi geniş yapraklı orman ve Botryochloum ischemum'un baskınlığı ve Juniperus communis L., J. sabina L., J. excelsa Bieb., J. foetidissima Willd., Pistacia mutica C.A.Mey., Pyrus salicifolia Pall., Rhamnus pallasii C.A., Rh. catharica L., Rh. spathulifolia C.A.Mey, Paliurus spina-christi Mill., vb. taksonların iştiraki ile ise otsu-arid seyrek orman birlikleri ve dağ bozkırlarının bir arada yayılış gösterdiği vurgulanmıştır (İbrahimov, Cabbarov vd., (2018). Bu alanlarda yayılış gösteren; Stachys inflata Benth., Thymus collinus Bieb., Th. kotschyanus Boiss. et Hohen dağ-kserofit bitki birliklerinde daha geniş yayılım göstermektedirler (Guseynova \& İbrahimov, 2018; Guseynova vd., 2018; Cabbarov vd., (2012).

Şahbuz ve Ordubad arazilerinde kserofit karakterli seyrek çalı ve ağaç türleri arasında baskın durumda frigana birliklerinin yayılış gösterdiği belirlenmiştir. İbrahimov vd., (2018) bölgenin frigana vejetasyonun sinıflandırılmasına yönelik çalışmasında, bölgede Astragalo-Brometea Quzel 1973 sinfina ait 1 ordo (Astragalo-Acanthalimonetalia); 2 alyans (Thymeto-Acantholimonion ve Asracanthetion mycrophyllae) ve 3 bitki birliğinin (Thymeto-Onobrychetum cornutae, Thymeto-Acantholimonetum bracteatumae, Amygdaleto-Astracantetum mycrophyllae) olduğunu ve bu birliklerin geniş yayılış gösterdiği vurgulanmıştır (İbrahimov vd., 2018).

Nahçıvan arazisinde bundan başka Celtis caucasica Willd., C. tournefortii Lam., C. glabrata Planch, Amygdalus fenzliana Lipsky, Rhus coriaria L. vb. yaprak döken çalı ve ağaç türlerinin oluşturduğu seyrek orman birliklerine de rastlanılmaktadır (Talibov \& Ibrahimov, 2010; Talibov vd., 2018).

Amelanchier ovalis Medik., Ziziphus jujuba Mill, Centranthus longifolius Stev., Ribes nigrum L., Pistacia mutica Fisch. \& C.A. Mey., Apium nodiflorum Lag. (Sin.: Helosciadium nodiflorum (L.) W.D.J. Koch) türleri Nahçıvan Özerk Cumhuriyeti arazisinde lokal yayılış göstermektedir (Guseynova vd., 2017).

Açık ve güneşli yamaçlarda yer alan armutlardan bazı bireyler 100-120 kg, bazı bireyler $200 \mathrm{~kg}$, erik $60-100$ $\mathrm{kg}$, kuş armudu 14-20, elma 150-180 (300 kg), ağaçbaşına 8$12 \mathrm{~kg}$ taze meyve vermiştir.

$\mathrm{Bu}$ araştırma sonucu bölgede meyve ve çiçek toplayıcıları için optimal zamanın her bir bitkinin yaşadığı yükselti ve coğrafik durum şartlarına göredeğişik zamanlara denk geldiği gözlenmiştir. Özellikle çiçek toplama zamanı erken ilkbahar, ilkbahar sonu, meyve olgunlaşma döneminin ise yaz, sonbahar ve sonbahar sonu olduğu belirlenmiştir.

$\mathrm{Bu}$ veriler ışı̆̆ında araştırma bölgesinde flora ve vejetasyonun bitki çeşitliliği açısından zengin olduğu gözükmektedir.

\section{KAYNAKLAR}

Bağırov, H.S. \& Hacıyev, C.E. (2013). Azerbaycan Respublikasının kırmızı kitabı. Nadir ve nesli kesilmekte olan bitki ve göbelek növleri. İkinci Baskı, Şerg-Qerb, 676s.

Azizbeyova, Ş.A. (1961). Geomorfologiya Nahçıvanskoy ASSR. Gos.nauç.-tekn.izd.literatur1 po geologii i okrane nedr., Moskova, 13-198.

Atamov, V. (2002). Azerbaycan'ın bozkır vejetasyonunun fitocoğrafik bölgeleri. Ot sistematik Botanik Dergisi, 9(2), 101-116. 
Beydeman, I.N. (1954). Metodika fenologiçeskich nablyudenii prigeobotaniçeskich issledovaniyach. İzd. AN SSSR, M.L.

Gadjiyev, V.D. (1970). Visokogornaya rastitelnost Bolşhogo Kafkaza $i$ ee xozyaystvennaya znaçeniya. Baku, Elm, 280s.

Gadjiyev,V.D., Kuliyeva, X.G. \& Vagabov, Z.V. (1979). Flora $i$ rastitelnost visokogorii Talışha. Bakü, Elm, 148s.

Gadjiyev, V.D., Aliyev, D.A., Kuliyev, V.Ş. \& Vagabov, Z.B. (1990). Visokogornaya rastitelnost Malogo Kafkaza. Baku, Elm, 210s.

Çerepanov, S.K. (1995). Sosudistie rasteniya Rossii i sopredelnich gosudarstv (vı predelach bıvşevgo SSSR. Petersburg: Mir i semya, $992 \mathrm{~s}$.

Ganbarli, A.A. (1973). Stroenie, biologiçeskaya $i$ chozyaystvennaya produktivnost nekotorlk friganoidnı fitosenozov Nakhcevanskoy ASSR. Diss. na soisk. Uç. Stepen. Avtoref. kand. biol. nauki, 31s.

Grossheym, A.A. (1936). Rastitelnıy resursı Kafkaza. Moskova, MOIP, 435s.

Grossheym, A.A. (1948). Rastitelnıy pokrov Kavkaza. Izd. MOIP, Moskova-Leningrad, 248s.

Grossgeym, А.A. (1939-1967). Флора Кавказа.(1-7 cilt), Izd.vo Azerb. Filiala Akadem. Nauk SSSR.Baku.

Guseynova, A.E. \& İbragimov, A.S. (2018). Efirnoe maslo $i$ himiçeskkiy sostav vidov Th. kotschyanus и Th. Collinus// Ministerstvo Prosveshenie Az. Resp., Nauçnıe Trusı NGU, Geyrat, 7(88), 20-26.

Guseynova, A.E., İbragimov, A.Ş. \& Nabiyeva, F.H. (2012). Efirnoe maslo i khimiçeskiy sostav nekotorih perspektivnı vidov shalfeya roda Salvia L. rasprostranyonennie na teritorii Nakhecevanskoy Avronomnoy Respubliki. Journal of Academy İzd.vo Problemı Nauki, 4(31), 13-16.

Cabbarov, T.M., Gurbanov, E.M. \& Ibragimov, A.Ș. (2012). Friganoidı na territorii Nakhçıvanskoy AR. Trudl Sentralnogo Botaniçeskogo sada. Tom X. Baku, "Elm", 295-300s.

Karyagın, I.I. (1950-1961). Flora Azerbaydjana, (1-8 cilt) Izd.vo AN Azerb. SSR, Baku.

Konspekt floraKavkaza. (2003). Tom 3, ch. 2./ Volume 3, b. 2., Petersburg.

Koldayev, V.H. (1972). Zagotovka dikorastuşich pişevich produktov. Moskova Lesnaya promışlennost, $94 \mathrm{~s}$.

Ibrahimov, A.Ş. (2005). Rastitelnost Nakheçevanskoy Avtonomnoy Respubliki ee narodnokozyaystvennoe znaçenie. Baku, Elm, $230 \mathrm{~s}$.

İbrahimov, A.S. (2007). Rastitelnost Nakhiçevanskoy Avtonomnoy Respubliki ee proizvoditelnost $i$ botaniko-geografiçeskoe rayonirovanie. Avtoreferat doktora biologiçeskikh nauk. Baku, 44s.

İbragimov, A.S. \& Nabiyeva, F.H. (2018). Vidovoy sostav flor Semeystva Bedrentsevı/Nahçıvanskoy Avtonomniy Respubliki. Gyandjinskiy Gosudarstvennıy Universtitet, Aktualnıe voprosı sovremennoy estestvennoe znaçenie. Materialı Vsesoyuznoy nauçnoy kenferebtsii, Gyandja, 45-49s.

İbrahimov, A.S., Jabbarov, M.T. \& Nabiyeva, F.H. (2018). Redkie endemiçnı vidı Poaceae Barnhart. $i$ voprosı ich ochranı// AMBA"Botanik Çalışmalarda yeni çă̆ırışlar" AMEA Botanika İnstitutu ve Azerbaycan Botanikler
Cemiyyetinin akad. V.C. Haciyevin 90 illiyine hesr edilmiş konfrans materialları, 20-21 iyun. Bakü, 33-35

İbrahimov, E., Cabbarov, M., Nabiyeva, F. \& Atamov, V. (2018). Nahcivan'ın Jeobotaniki Bölgelendirilmesine Katkılar. Anadolu Çevre Hayvancılık Dergisi, 3(3), 145$151 \mathrm{~s}$.

Magakyan A.K. (1941). Rastitelnost Armyanskoy SSR. M., İzd-vo AN CCCR.

Movsumova, F.K. \& Ibrahimov, A.S. (1986). İzmenenie florı pustın Nakheçenanskoy ASSR. Tezisı dokladov Respublikanskoy nauçnoy konferentsii "Materialnodukhovnıe bogatstvo Nakheçevanskoy ASSR i nauçnotekniçeskiy progress". 22-23 aprel, Nakheçevans. 42s.

Metogika fenologiçeskikh nablyudeniya pri botaniçeskikh issledovaniyakh. (1966). Moskova AN SSSR, 152s.

Prilipko, L.I. (1939). Rastitelnıe otnoşenie vi Nakheçevanskoy ASSR.//Trudı Botaniçeskogo İnstituta, T.VII, İzd. Az. FAN, 196s.

Prilipko, L.I. (1970). Rastitelnıy pokrov Azerbaidjsana. Bakü: Elm, $169 \mathrm{~s}$.

Pimenov, M.G., Nabieva, F.C., İbadullaeva, S.D. \& İbrahimov, A.İ. (2018). Heliosciadium nodiflorum noviy rod i vid Umbelliferae dlya florı Azerbaidjana i vsego Kavkaza. Botaniçeskiy jurnal. L., Nauka, 103(4), 517-528.

Polevaya geobotanıka. (1959-1976). M.-L.: İzd. AN SSSR, Vol.15.

Talıbov, T.G. (2001). Nahcıvan MR-ın Flora Biyoçeşitliliği ve Onun Nadir Növlerinin Korunması. Baku: Elm, 191s.

Talibov, T.G. \& İbrahimov A.S. (2008). Taksonomiçeskiy spektr (Vısşie sporovie, golosemennıe i porıtosemennıe rasteniya) florı Nakheçevanskoy Avtonomnoy Respubliki. Nakhıçevan: Adjami, 364s.

Talıbov, T.G. (2003). Bioraznoobraziya florı Nakheçevanskoy Avtonomnoy Respubliki, ey ratsionalnoe ispolzovaniya i okhranı. Avtoref. Diss. Doktora biologiçeskihk nauk. Baku: 63s.

Talıbov, T.G. \& Ibrahimov, A.S. (2010). Krasnaya knig Nakheçevanskoy Avtonomnoy Respubliki. Nakheçevan: Adjemi, 676s.

Talıbov, T.G., İbrahimov, A.S., İbrahimov, A.M., Alekperov, R.A. \& İsmailov, A.C. (2018). Lekarstvennıe Rasteniya Nahcivanskoy Avtonomnoy Respubliki// OrechovoZuevo: Redaktsionno-izdatelskiy otdel GGGU, $463 \mathrm{~s}$.

Sokhadze, E.B. (1982). Izvestnysaaki $i$ Rastitelnost, Metsniereba,Tbilisi, 160s.

*Corresponding author's:

Musa CABBAROV

Bakü Devlet Üniversitesi, Biyoloji Fakültesi, Botanik Kürsüsü, Halilov 23, Bakü/Azerbaycan.

\E-mail: musa_telman@mail.ru

ORCID : https://orcid.org/0000-0003-0386-2207

Telefon : :+99(450) 3740019 